TITLE:

\title{
Nickel Alloying Effect on Formation of Cobalt Nanoparticles and Nanowires via Electroless Deposition under a Magnetic Field
}

\section{AUTHOR(S):}

Kawamori, Makoto; Yagi, Shunsuke; Matsubara, Eiichiro

\section{CITATION:}

Kawamori, Makoto ...[et al]. Nickel Alloying Effect on Formation of Cobalt Nanoparticles and Nanowires via Electroless Deposition under a Magnetic Field. Journal of The Electrochemical Society 2011, 159(2): E37-E44

ISSUE DATE:

2011-12

URL:

http://hdl.handle.net/2433/155957

RIGHT:

(c)2011 The Electrochemical Society 


\title{
Nickel Alloying Effect on Formation of Cobalt Nanoparticles and Nanowires via Electroless Deposition under a Magnetic Field
}

\author{
Makoto Kawamori, ${ }^{a, *, z}$ Shunsuke Yagi, ${ }^{b, * *}$ and Eiichiro Matsubara ${ }^{a}$ \\ ${ }^{a}$ Department of Materials Science and Engineering, Kyoto University, Kyoto 606-8501, Japan \\ ${ }^{b}$ Nanoscience and Nanotechnology Research Center, Osaka Prefecture University, Osaka 599-8570, Japan
}

\begin{abstract}
Co-Ni nanowires 40-100 $\mathrm{nm}$ in diameter with several dozen $\mu \mathrm{m}$ of length were prepared via electroless deposition under a magnetic field. The formation of $\mathrm{Co}-\mathrm{Ni}$ nanowires was investigated by an in-situ mixed potential measurement and a cyclic voltammetry combined with a quartz crystal microbalance electrode. These electrochemical measurements revealed that the deposition rate of nickel on nickel is lower than that of cobalt on cobalt. Nickel works as an inhibitor in a growth process of Co-Ni alloys. Thus, the thickness of Co-Ni alloy nanowires is drastically reduced by the addition of $\mathrm{Ni}(\mathrm{II})$ in solution. The morphology of Co-Ni nanowires is also strongly affected by the magnetization of $\mathrm{Co}-\mathrm{Ni}$ alloy nanoparticles which are precursors in the formation of nanowires. Both the magnetization and the deposition rate in Co-Ni alloys are the key parameters to control the aspect ratio and surface morphology of nanowires.
\end{abstract}

C) 2011 The Electrochemical Society. [DOI: 10.1149/2.062202jes] All rights reserved.

Manuscript submitted August 29, 2011; revised manuscript received October 26, 2011. Published December 20, 2011.

Nanowires of iron group metals $(\mathrm{Fe}, \mathrm{Co}, \mathrm{Ni}$ ) are attractive for applications to catalytic materials as well as magnetic materials with the magnetic shape anisotropy. ${ }^{1}$ Numerous methods for synthesis of iron group nanowires have been reported using the template-assisted electrodeposition, ${ }^{2-4}$ organometallic routes, ${ }^{5,6}$ polyol reduction, ${ }^{7,8}$ and electroless deposition under an external magnetic field. ${ }^{9,10}$ Especially, the electroless deposition has a great advantage because the nanowires with a wide variety of compositions and sizes can be fabricated in a large-scale with a relatively simple method.

We have extensively studied the fabrication of metallic nanoparticles such as copper, ${ }^{11,12}$ cobalt, ${ }^{13,14}$ nickel, ${ }^{15}$ and Co-Ni alloy ${ }^{16}$ by the electroless deposition method and also developed the monitoring method of the reaction process by adopting a concept of a mixed potential which is a good indicator of a reduction ability in solution. Recently, we have succeeded in a fabrication of nickel nanowires by applying this method of nanoparticles and also proposed the formation mechanism of nanowires. ${ }^{17}$ In the synthesis of nanowires under a magnetic field, the magnetic properties of nanoparticles definitely affect the morphology of nanowires because the nanoparticles are firstly formed prior to the formation of nanowires. ${ }^{17}$ Thus, in the present work, the effect of a magnetic field on the formation of nanowires was investigated in the Co-Ni system. First, the electrochemical behavior in the formation of Co-Ni nanoparticles was carefully studied using an in-situ mixed potential measurement, an in-situ quartz crystal microbalance (QCM) measurement, and a cyclic voltammetry with a QCM electrode. Then, the formation of Co-Ni nanowires was discussed.

\section{Experimental}

The reaction solutions were prepared using cobalt chloride hexahydrate $\left(\mathrm{CoCl}_{2} \cdot 6 \mathrm{H}_{2} \mathrm{O}\right)$ and nickel chloride hexahydrate $\left(\mathrm{NiCl}_{2} \cdot 6 \mathrm{H}_{2} \mathrm{O}\right)$ as a source of cobalt and nickel ions, ethylene glycol (EG) as a solvent, and hydrazine monohydrate $\left(\mathrm{N}_{2} \mathrm{H}_{4} \cdot \mathrm{H}_{2} \mathrm{O}\right)$ as a reducing agent. Sodium hydroxide $(\mathrm{NaOH})$ was used as a source of $\mathrm{OH}^{-}$ions. Chloroplatinic acid hexahydrate $\left(\mathrm{H}_{2} \mathrm{PtCl}_{6} \cdot 6 \mathrm{H}_{2} \mathrm{O}\right)$ was used as a nucleating agent. These reagents are all reagent-grade (Nacalai Tesque, Inc.) and used without further purification.

First, $27 \mathrm{~cm}^{3}$ EG solution containing $0.10 \mathrm{M}$ metallic salts ( $\left[\mathrm{CoCl}_{2}\right]$ $+\left[\mathrm{NiCl}_{2}\right]=0.10 \mathrm{M}$ ) and $0.3 \mathrm{M} \mathrm{NaOH}$ was prepared, where $\mathrm{M}$ is mol $\mathrm{dm}^{-3}$. For the experiments with a nucleating agent, $0.20 \mathrm{mM} \mathrm{H}_{2} \mathrm{PtCl}_{6}$ was added. The same amount of EG solution $\left(27 \mathrm{~cm}^{3}\right)$ containing 1.00 $\mathrm{M} \mathrm{N}_{2} \mathrm{H}_{4}$ and $0.1 \mathrm{M} \mathrm{NaOH}$ was also prepared. The temperature of the

\footnotetext{
* Electrochemical Society Student Member.

** Electrochemical Society Active Member.

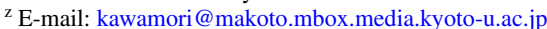

solutions was kept at $353 \mathrm{~K}$ with nitrogen gas bubbling to remove the dissolved oxygen. The metallic salt solution and the hydrazine solution were mixed at $353 \mathrm{~K}$ to start the reaction. The reaction solution was agitated at a rate of $500 \mathrm{rpm}$ with a magnetic stirring unit at $353 \mathrm{~K}$ during the reaction for the syntheses of Co-Ni particles. For the syntheses of Co-Ni wires, the reaction solution was kept at $353 \mathrm{~K}$ in a water bath located inside the two parallel neodymium magnets $(100 \times 100 \mathrm{~mm})$ separated $100 \mathrm{~mm}$ apart. The magnetic field inside the magnets was about 1.0-2.0 kOe, which was measured by a Tesla meter (KANETEC Co., Ltd., TM-601). After the reaction, particles and wires were washed several times with ethanol.

The morphology of precipitates was observed using a fieldemission-scanning electron microscope (JEOL Ltd., JSM-6500F). The mean diameter and size distribution of the $\mathrm{Co}-\mathrm{Ni}$ particles were determined by image analysis for randomly selected 600 particles in each sample. The compositions of Co-Ni particles and wires were analyzed with energy-dispersive X-ray (EDX) spectrometry. The crystalline structure of precipitates was investigated by X-ray diffraction (XRD, Rigaku Co., Ltd., RINT-2200) using $\mathrm{Cr} K \alpha$ radiation. A superconducting quantum interference device (Quantum Design, Inc., MPMS SQUID XL) was used to measure the magnetic hysteresis curves of the particles at room temperature. During the syntheses of Co-Ni particles, the gold-sputtered QCM electrode (SEIKO EG\&G QA-A9M-AU) was immersed in the reaction solution and the mixed potential of the QCM electrode was measured by a potentiostat/galvanostat (Hokuto Denko Co., Ltd., HA-151) using a Ag/AgCl (3.33 M KCl) electrode (Horiba 2565A-10T) as a reference electrode. The weight of deposits on the QCM electrode, $\triangle m$, was calculated from the change in resonance frequency of the QCM electrode, $\Delta f$, by Sauerbrey's equation; ${ }^{18}$

$$
\Delta m=-\frac{A \sqrt{\rho_{q} \mu_{q}}}{2 f_{0}^{2}} \Delta f
$$

where $f_{0}$ is the frequency of the QCM electrode before the deposition, $A$ is the active area of the QCM electrode $\left(0.196 \mathrm{~cm}^{2}\right), \rho_{q}$ is the density of quartz $\left(2.648 \mathrm{~g} \mathrm{~cm}^{-3}\right)$, and $\mu_{q}$ is the shear modulus of quartz $\left(2.947 \times 10^{11} \mathrm{~g} \mathrm{~cm}^{-1} \mathrm{~s}^{-2}\right)$. The cyclic voltammograms were also measured by the potentiostat/galvanostat using a gold or nickelsputtered QCM electrode (SEIKO EG\&G QA-A9M-NI) as a working electrode, a platinum electrode $(20 \times 20 \mathrm{~mm})$ as a counter electrode, and a $\mathrm{Ag} / \mathrm{AgCl}$ electrode as a reference electrode.

\section{Results}

Figure 1 shows scanning electron microscopy (SEM) images and size distributions of particles synthesized in the different concentration ratios of $\mathrm{Co}(\mathrm{II})$ to $\mathrm{Ni}(\mathrm{II})$ in the reaction solutions. The mean diameter 
In the absence of $\mathrm{H}_{2} \mathrm{PtCl}$
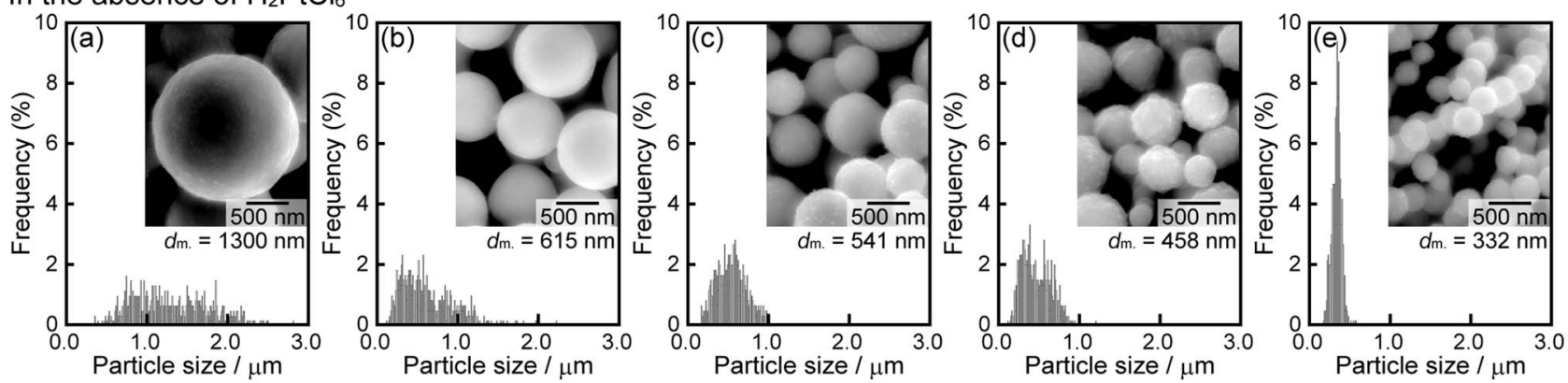

In the presence of $0.10 \mathrm{mM} \mathrm{H}_{2} \mathrm{PtCl}_{6}$
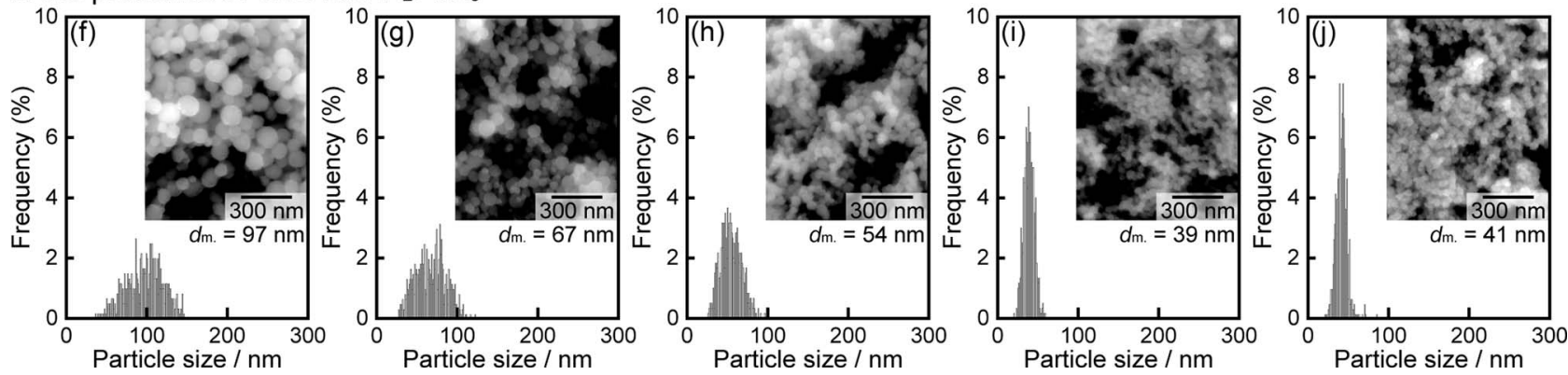

Figure 1. SEM images and size distribution of the particles synthesized from the solutions containing (a) $0.050 \mathrm{M} \mathrm{Co}$ (II), (b) $0.035 \mathrm{M} \mathrm{Co}$ (II) - $0.015 \mathrm{M}$ Ni(II),

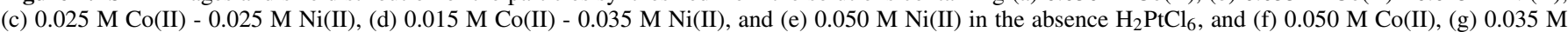
$\mathrm{Co}(\mathrm{II})-0.015 \mathrm{M} \mathrm{Ni}(\mathrm{II})$, (h) $0.025 \mathrm{M} \mathrm{Co}$ (II) $-0.025 \mathrm{M} \mathrm{Ni}(\mathrm{II})$, (i) $0.015 \mathrm{M} \mathrm{Co(II)}-0.035 \mathrm{M} \mathrm{Ni}$ (II), and (j) $0.050 \mathrm{M} \mathrm{Ni(II)}$ in the presence of $0.10 \mathrm{mM} \mathrm{H}_{2} \mathrm{PtCl} l_{6}$. Mean diameter $d_{\mathrm{m}}$. is also indicated.

of the particles is also indicated. In the absence of $\mathrm{H}_{2} \mathrm{PtCl}_{6}$, the mean particle diameters are $1300 \mathrm{~nm}$ and $330 \mathrm{~nm}$ at $[\mathrm{Co}(\mathrm{II})]:[\mathrm{Ni}(\mathrm{II})]$ $=100: 0$ and $0: 100$, respectively (Fig. 1a and 1e). The particle size decreases and the size distribution becomes sharper with an increase in a concentration of $\mathrm{Ni}(\mathrm{II})$ (Fig. 1b-1d). By the addition of $\mathrm{H}_{2} \mathrm{PtCl}_{6}$, the particle size largely decreased in a whole ratio of $\mathrm{Co}(\mathrm{II})$ to $\mathrm{Ni}$ (II) (Fig. 1f-1j). The nucleating agent such as $\mathrm{H}_{2} \mathrm{PtCl}_{6}$, whose redox potential is much higher than that of the objective metal, provides many heterogeneous nucleation sites, resulting in the formation of abundant and fine particles. ${ }^{19,20}$ The provided platinum nuclei divides the nucleation and growth stages during the formation of Co-Ni particles, which gives us a sharper size distribution. On the contrary, a reduction of the Co-Ni particle size by the addition of $\mathrm{Ni}(\mathrm{II})$ is observed with and without $\mathrm{H}_{2} \mathrm{PtCl}_{6}$. The standard electrode potential of $\mathrm{Ni}(\mathrm{II}) / \mathrm{Ni}$ redox pair $\left(E_{\mathrm{Ni}(\mathrm{II}) / \mathrm{Ni}}=-0.250 \mathrm{~V}\right.$ vs. SHE$)$ is close to that of $\mathrm{Co}(\mathrm{II}) / \mathrm{Co}$ $\operatorname{pair}\left(E_{\mathrm{Co}(\mathrm{II}) / \mathrm{Co}}=-0.277 \mathrm{~V} \text { vs. SHE) }\right)^{21}$ Thus, the formation of smaller particles by the addition of $\mathrm{Ni}(\mathrm{II})$ is not explained like the case of the nucleating agent of $\mathrm{H}_{2} \mathrm{PtCl}_{6}$

The atomic ratios of cobalt to nickel in the particles are almost equal to the ratios of $\mathrm{Co}$ (II) to $\mathrm{Ni}$ (II) ions in solution as it is seen in Table I. Figure 2 shows the atomic ratios of cobalt and nickel at the points indicated in the SEM images of Co-Ni alloy particles. A small composition gradient is observed in the particles at all concentration ratios. The ratio of cobalt is slightly higher at the core of the particles than at the edge. In contrast, that of nickel is lower at the core of the particles than at the edge. Consequently, although atomic concentrations of the particles are equal to the nominal concentration in a macro-scopic scale, the concentration fluctuations exist in a nano-meter scale.

Figure 3 shows XRD patterns of the particles. The hexagonal closepacked (hcp) peaks of cobalt and the face-centered cubic (fcc) peaks of nickel are observed at $[\mathrm{Co}(\mathrm{II})]:[\mathrm{Ni}(\mathrm{II})]=100: 0$ and $0: 100$, respectively. In the XRD patterns of Co-Ni alloy particles, both fcc and hcp peaks are observed. The intensity of (100) hcp cobalt peak around $63.8^{\circ}$ decreases with increasing a concentration of $\mathrm{Ni}(\mathrm{II})$. Additionally, a symmetry of the largest peak around $68.5^{\circ}$ improves at a higher concentration of $\mathrm{Ni}(\mathrm{II})$, indicating that the contribution of peaks due to fcc structure becomes dominant. By the addition of $\mathrm{H}_{2} \mathrm{PtCl}_{6}$, the peak width slightly becomes broader in each concentration ratio (Fig. $3 \mathrm{f}-3 \mathrm{j}$ ), which is due to a decrease in the crystallite size. In pure cobalt, a hcp structure is stable at the room temperature and transforms to the fcc phase at $695 \mathrm{~K}$ according to the Co-Ni phase diagram. $^{22}$ This allotropic transformation temperature decreases by alloying with nickel. At present reaction temperature of $353 \mathrm{~K}$, the hcp and fcc phases are stable below about 25 atom\% Ni and above 35 atom\% $\mathrm{Ni}$, respectively. Both phases coexist between these nickel concentrations. Thus, both the fcc and hcp phases are the equilibrium phase at $\mathrm{Co}: \mathrm{Ni}=70: 30($ atom\%) and the fcc phase at $\mathrm{Co}: \mathrm{Ni}$ $=50: 50$ and $30: 70($ atom\%) at $353 \mathrm{~K}$. Small diffuse peaks due to hep cobalt disappear by annealing the as-prepared Co-Ni alloy particles at $623 \mathrm{~K}$ in Ar atmosphere for 16 hours. Figure 4 shows the SEM images of the annealed particles. Neither sintering nor

Table I. Atomic ratio of metal in the particles synthesized by changing the concentration ratio of $\mathrm{Co}$ (II) to $\mathrm{Ni}(\mathrm{II})$ in the reaction solution.

Concentration ratio

of metallic species in

Atomic ratio of

the reaction solution

With or without metal (atom\%)

[Co(II)] : [Ni(II)]

$\mathrm{H}_{2} \mathrm{PtCl}_{6}$

Co Ni

(a) $100: 0$

100.0 0.0

(b) $70: 30$

(c) $50: 50$

(d) $30: 70$

(e) $0: 100$

(f) $100: 0$

(g) $70: 30$

(h) $50: 50$

(i) $30: 70$

(j) $0: 100$
70.3

50.4

29.9

0.0

100.0

69.8

49.4

30.3

0.0
29.7

49.6

70.1

100.0

0.0

30.2

50.6

69.7

100.0 


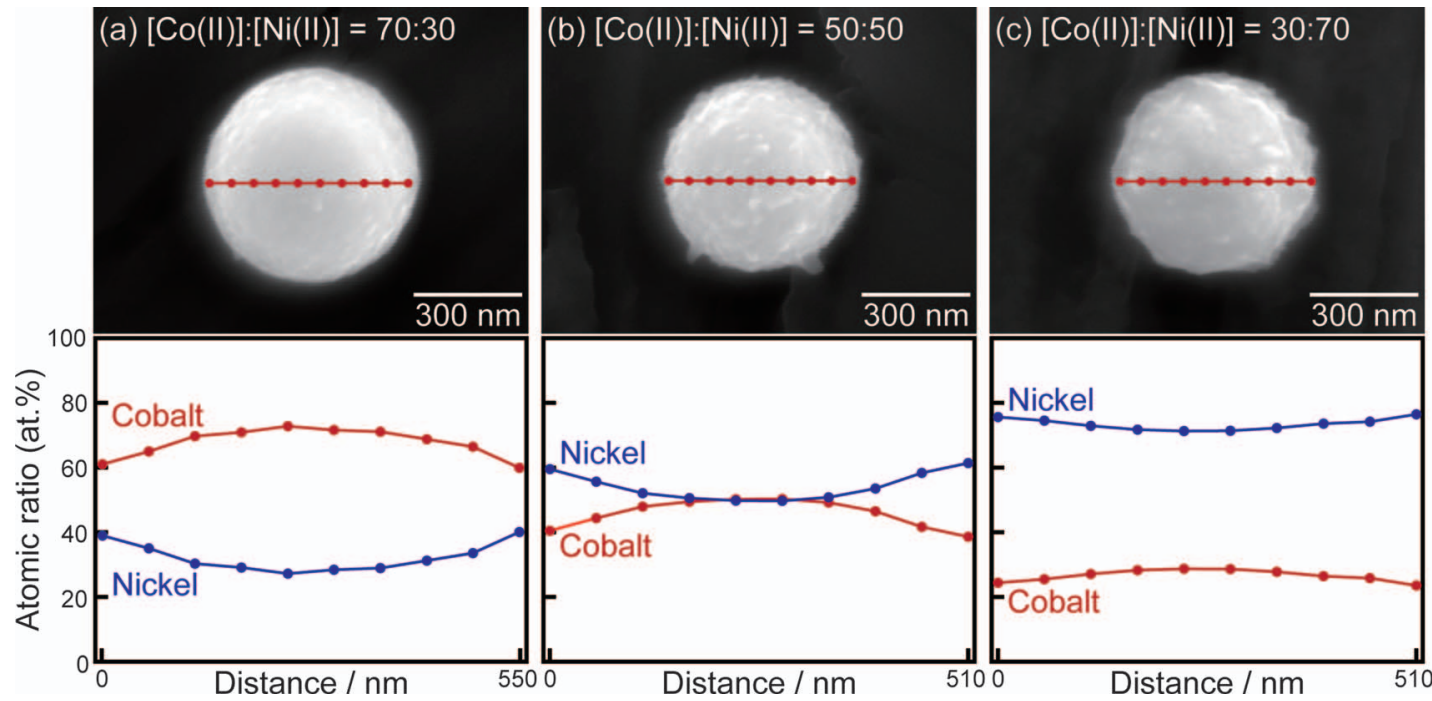

Figure 2. SEM images and atomic ratios of cobalt and nickel of particles synthesized from the solutions containing (a) $0.035 \mathrm{M} \mathrm{Co}$ (II) - $0.015 \mathrm{M} \mathrm{Ni(II),} \mathrm{(b)} 0.025$ $\mathrm{M} \mathrm{Co}(\mathrm{II})-0.025 \mathrm{M} \mathrm{Ni}(\mathrm{II})$, and (c) $0.015 \mathrm{M} \mathrm{Co}(\mathrm{II})-0.035 \mathrm{M} \mathrm{Ni(II)}$.

agglomeration among the particles is observed. Additionally, the surface of the annealed particles is relatively smoother than that of the as-prepared particles. The XRD patterns of annealed particles and the lattice parameters calculated by the position of the fcc 200 peak at around $80^{\circ}$ are shown in Figure 5. The peaks in the XRD patterns of annealed particles become sharper because of the grain growth by annealing. The $100 \mathrm{hcp}$ peak at $63.8^{\circ}$ observed in the as-prepared particles at $[\mathrm{Co}(\mathrm{II})]:[\mathrm{Ni}(\mathrm{II})]=50: 50$ and $30: 70$ (Fig. $3 \mathrm{c}$ and $3 \mathrm{~d})$ completely disappeared after annealing. This is consistent with the phase expected in the phase diagram. As shown in Fig. 5B, the lattice parameters change approximately with the linear function of the composition of $\mathrm{Ni}$ (II) between the two lattice parameters of metastable fcc cobalt and fcc nickel, obeying the Vegard's law. ${ }^{22,23}$ This indicates that Co-Ni solid solutions were formed in the particles after annealing.

Figure 6 shows the weight change of metals deposited on the QCM substrate during the nanoparticles formation with different concentration ratios of $\mathrm{Co}(\mathrm{II})$ to $\mathrm{Ni}(\mathrm{II})$. At $[\mathrm{Co}(\mathrm{II})]:[\mathrm{Ni}(\mathrm{II})]=100: 0$ in the absence of $\mathrm{H}_{2} \mathrm{PtCl}_{6}$ (Fig. 6a), the cobalt deposition is observed at about 4 minutes after mixing the solutions containing $\mathrm{Co}$ (II) and hydrazine. The weight of cobalt reaches $105 \mu \mathrm{g}$ in 17 minutes, which
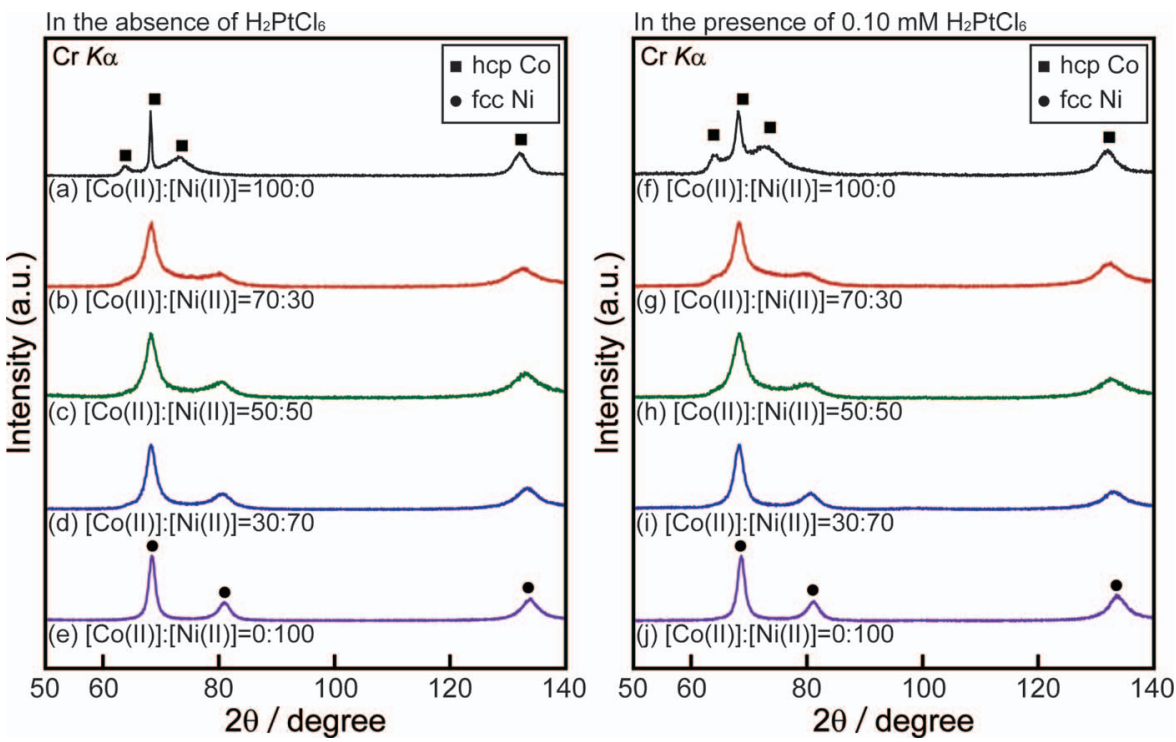

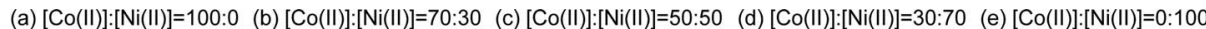

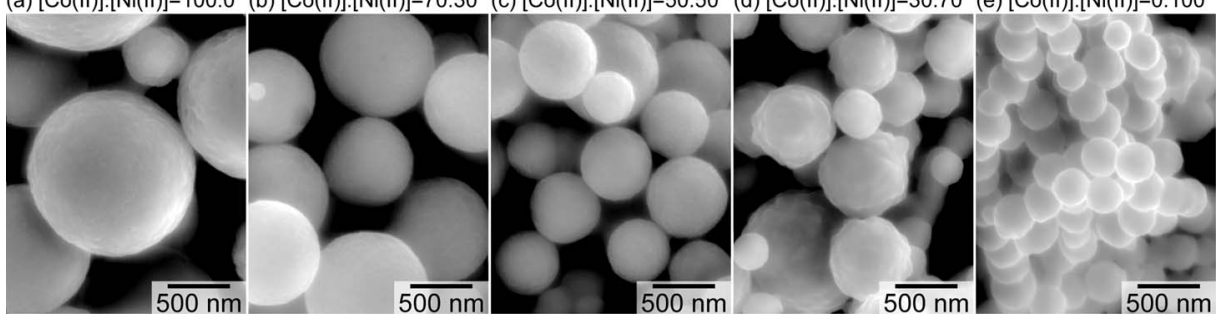

Figure 3. XRD patterns of the particles synthesized from the solutions containing (a) $0.050 \mathrm{M} \mathrm{Co}$ (II) (b) $0.035 \mathrm{M} \mathrm{Co}$ (II) $-0.015 \mathrm{M} \mathrm{Ni}(\mathrm{II})$, (c) $0.025 \mathrm{M}$ Co(II) $-0.025 \mathrm{M} \mathrm{Ni}$ (II), (d) $0.015 \mathrm{M} \mathrm{Co}$ (II) $-0.035 \mathrm{M}$ $\mathrm{Ni}(\mathrm{II}),(\mathrm{e}) 0.050 \mathrm{M} \mathrm{Ni}(\mathrm{II})$ in the absence of $\mathrm{H}_{2} \mathrm{PtCl}_{6}$, and (f) $0.050 \mathrm{M} \mathrm{Co}$ (II), (g) $0.035 \mathrm{M} \mathrm{Co}$ (II) $-0.015 \mathrm{M}$ $\mathrm{Ni}(\mathrm{II})$, (h) $0.025 \mathrm{M} \mathrm{Co}$ (II) $-0.025 \mathrm{M} \mathrm{Ni}$ (II), (i) 0.015 $\mathrm{M} \mathrm{Co}(\mathrm{II})-0.035 \mathrm{M} \mathrm{Ni}(\mathrm{II}),(\mathrm{j}) 0.050 \mathrm{M} \mathrm{Ni}$ (II) in the presence of $0.10 \mathrm{mM} \mathrm{H}_{2} \mathrm{PtCl}_{6}$.

Figure 4. SEM images of the particles of (a) to (e) in Figure 1 annealed at $623 \mathrm{~K}$ for 16 hours. 

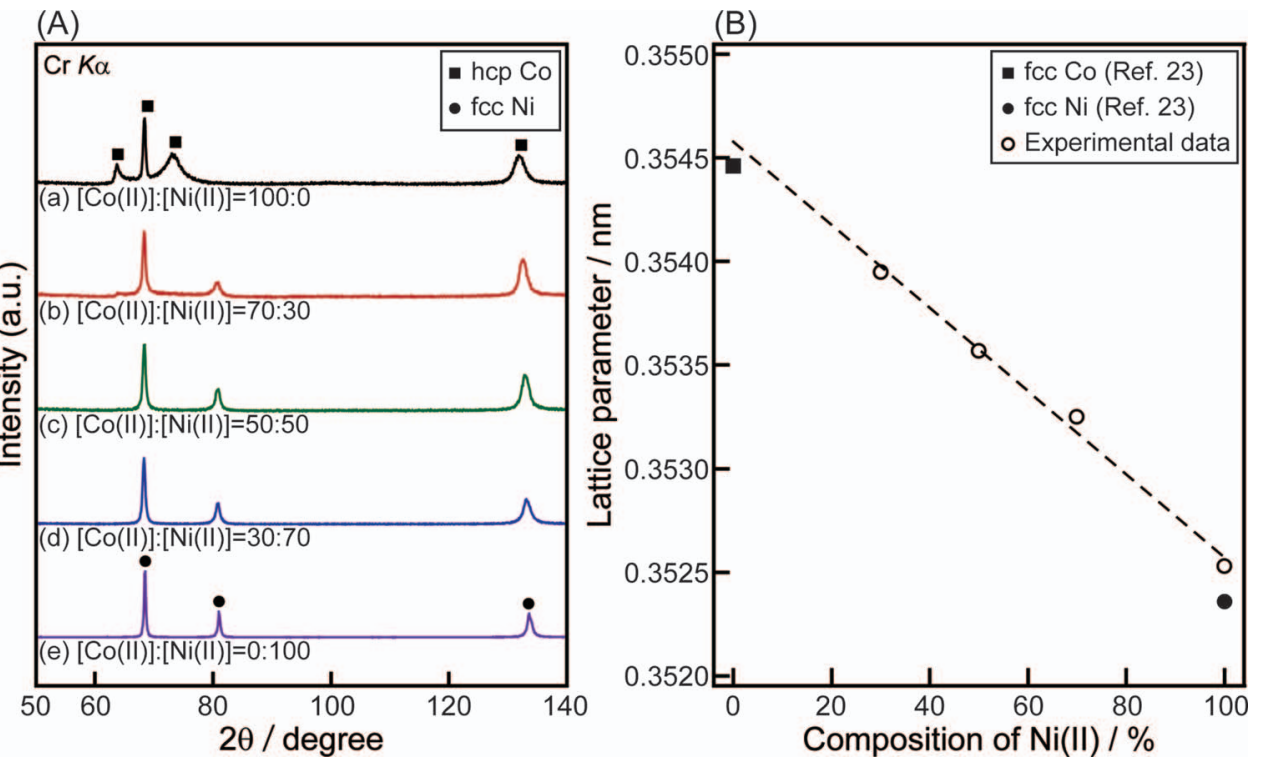

Figure 5. (A) XRD patterns of the particles of (a) to (e) in Figure 1 annealed at $623 \mathrm{~K}$ for 16 hours and (B) change in lattice parameters of annealed particles with composition of $\mathrm{Ni}(\mathrm{II})$.

is the maximum value observable in the present system. The slope of the curve, which is the deposition rate, becomes smaller and the final weight of metal deposited on a QCM substrate decreases with an increase in a concentration of $\mathrm{Ni}(\mathrm{II})$. Also, the amounts of cobalt in the presence of $\mathrm{H}_{2} \mathrm{PtCl}_{6}$ (Fig. 6f) is about $4 \mu \mathrm{g}$ which is much smaller than that in the absence of $\mathrm{H}_{2} \mathrm{PtCl}_{6}$ (Fig. 6a). Considering that the same amount of $\mathrm{Co}$ (II) dissolves in the reaction solution in the both cases and the formation of platinum particles provides nucleation sites of cobalt which suppresses the heterogeneous nucleation on the QCM substrate, we conclude that the decrease in the amounts deposited on a QCM substrate by the addition of $\mathrm{Ni}(\mathrm{II})$ is due to the enhancement of the homogeneous nucleation in the solution.

Figure 7 shows SEM images of wires synthesized from the solutions under a magnetic field at the different concentration ratios of $\mathrm{Co}(\mathrm{II})$ to $\mathrm{Ni}(\mathrm{II})$. While the surface of cobalt wires is relatively smooth

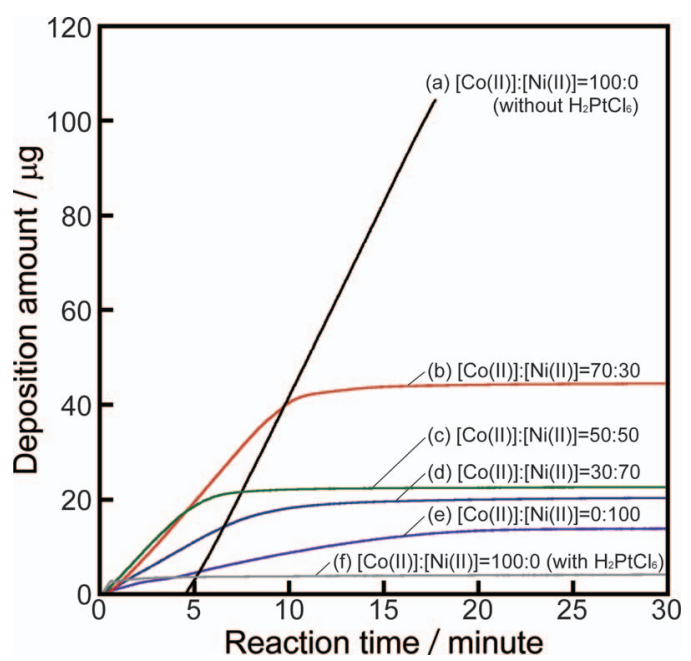

Figure 6. Weight of metal deposited on the gold-sputtered QCM substrate from the solutions containing (a) $0.050 \mathrm{M} \mathrm{Co}$ (II), (b) $0.035 \mathrm{M} \mathrm{Co(II)}-0.015$ $\mathrm{M} \mathrm{Ni(II),(c)} 0.025 \mathrm{M}$ Co(II) - $0.025 \mathrm{M} \mathrm{Ni}$ (II), (d) $0.015 \mathrm{M}$ Co(II) - $0.035 \mathrm{M}$ $\mathrm{Ni}(\mathrm{II})$, (e) $0.050 \mathrm{M} \mathrm{Ni}(\mathrm{II})$, and (f) $0.050 \mathrm{M} \mathrm{Co}$ (II). $\mathrm{H}_{2} \mathrm{PtCl}_{6}$ is added only in the solution (f).
(Fig. 7a), the surface of Co-Ni wires becomes rougher at a higher concentration of $\mathrm{Ni}$ (II) (Fig. 7b-7d) and beads-like wires were obtained at $[\mathrm{Co}(\mathrm{II})]:[\mathrm{Ni}(\mathrm{II})]=0: 100$ (Fig. 7e). The diameter of wires decreases with an increase in a concentration of $\mathrm{Ni}(\mathrm{II})$. Cobalt and Co$\mathrm{Ni}$ nanowires whose diameter is smaller than $100 \mathrm{~nm}$ were obtained by the addition of $0.10 \mathrm{mM} \mathrm{H}_{2} \mathrm{PtCl}_{6}$. Beads-like nickel nanowires of $40 \mathrm{~nm}$ in diameter were formed from the solution containing $0.050 \mathrm{M}$ $\mathrm{Ni}(\mathrm{II})$. It is likely that the formation of wire becomes more difficult at a higher $\mathrm{Ni}$ (II) concentration. It is also noted that the diameter of the nanoparticles without a magnetic field is close to that of the nanowires with a magnetic field at the same concentration ratio of $\mathrm{Co}$ (II) to $\mathrm{Ni}(\mathrm{II})$ (see Fig. 1 and Fig. 7, respectively).

Table II shows the atomic ratios of metals in the nanowires. The alloy compositions are close to the ratios of $\mathrm{Co}$ (II) to $\mathrm{Ni}$ (II) ions in solution as it is seen in the particles of Table I. Figure 8 shows XRD patterns of the wires. The peak positions and peak widths are almost the same as those of the particles in Fig. 3. Thus, the basic formation processes are similar in both nanoparticles and nanowires.

Table II. Atomic ratio of metal in the wires synthesized by changing the concentration ratio of $\mathrm{Co}(\mathrm{II})$ to $\mathrm{Ni}$ (II) in the reaction solution.

Concentration ratio

of metallic species in

the reaction solution

\begin{tabular}{|c|c|c|}
\hline \multirow{2}{*}{$\begin{array}{l}\text { With or without } \\
\qquad \mathrm{H}_{2} \mathrm{PtCl}_{6}\end{array}$} & \multicolumn{2}{|c|}{$\begin{array}{l}\text { Atomic ratio of } \\
\text { metal (atom\%) }\end{array}$} \\
\hline & Co & $\mathrm{Ni}$ \\
\hline- & 100.0 & 0.0 \\
\hline- & 70.5 & 29.5 \\
\hline- & 50.3 & 49.7 \\
\hline- & 30.4 & 69.6 \\
\hline- & 0.0 & 100.0 \\
\hline $\mathrm{x}$ & 100.0 & 0.0 \\
\hline $\mathrm{x}$ & 71.2 & 28.8 \\
\hline $\mathrm{x}$ & 51.4 & 48.6 \\
\hline $\mathrm{x}$ & 29.1 & 70.9 \\
\hline $\mathrm{x}$ & 0.0 & 100.0 \\
\hline
\end{tabular}


In the absence of $\mathrm{H}_{2} \mathrm{PtCl}_{6}$

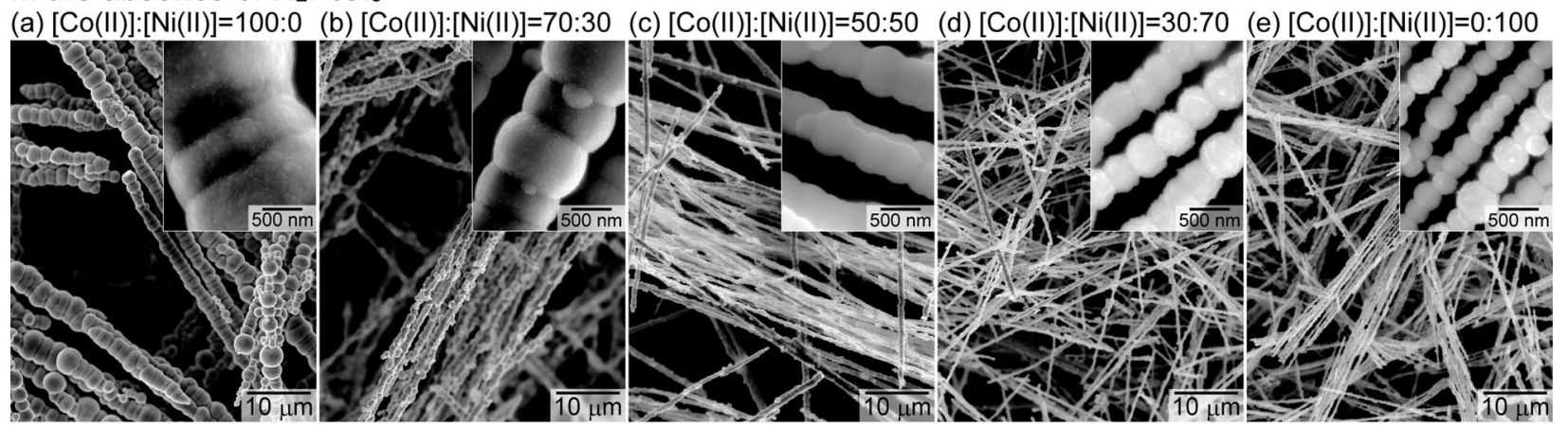

In the presence of $0.10 \mathrm{mM} \mathrm{H}_{2} \mathrm{PtCl}_{6}$
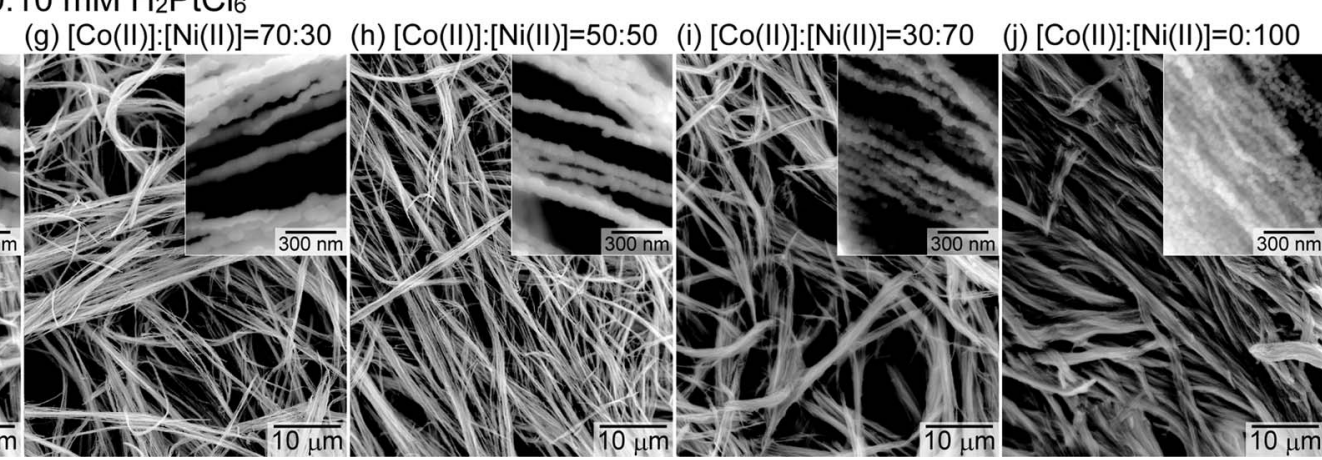

Figure 7. SEM images of the wires synthesized from the solutions containing (a) $0.050 \mathrm{M} \mathrm{Co}$ (II), (b) $0.035 \mathrm{M} \mathrm{Co}$ (II) - $0.015 \mathrm{M} \mathrm{Ni(II),} \mathrm{(c)} 0.025 \mathrm{M} \mathrm{Co}$ (II) - 0.025 $\mathrm{M} \mathrm{Ni}(\mathrm{II})$, (d) $0.015 \mathrm{M} \mathrm{Co}(\mathrm{II})-0.035 \mathrm{M} \mathrm{Ni}(\mathrm{II})$, and (e) $0.050 \mathrm{M} \mathrm{Ni}(\mathrm{II})$ in the absence $\mathrm{H}_{2} \mathrm{PtCl}_{6}$, and (f) $0.050 \mathrm{M} \mathrm{Co}(\mathrm{II}),(\mathrm{g}) 0.035 \mathrm{M} \mathrm{Co}$ (II) - $0.015 \mathrm{M} \mathrm{Ni}$ (II), (h) $0.025 \mathrm{M}$ Co(II) $-0.025 \mathrm{M} \mathrm{Ni}$ (II), (i) $0.015 \mathrm{M} \mathrm{Co}$ (II) - $0.035 \mathrm{M} \mathrm{Ni}$ (II), and (j) $0.050 \mathrm{M} \mathrm{Ni}$ (II) in the presence of $0.10 \mathrm{mM} \mathrm{H}_{2} \mathrm{PtCl}_{6}$.

\section{Discussion}

Formation of Co-Ni nanoparticles via electroless deposition.- In the formation process of nanoparticles by electroless deposition, the particle growth proceeds in the simultaneous oxidation reactions of the reducing agent and reduction reactions of metallic ions. Therefore, the polarization curves enable us to evaluate the particle growth rate. In the present process, the following hydrazine oxidation reaction mainly occurs as an anodic reaction:

$$
\mathrm{N}_{2} \mathrm{H}_{4}+4 \mathrm{OH}^{-} \rightarrow \mathrm{N}_{2}+4 \mathrm{H}_{2} \mathrm{O}+4 \mathrm{e}
$$

Figure 9 shows anodic polarization curves measured in EG containing $0.2 \mathrm{M} \mathrm{NaOH}$ and $0.50 \mathrm{M} \mathrm{N}_{2} \mathrm{H}_{4}$ using cobalt and nickel substrates as a working electrode. The anodic current due to the oxidation of hydrazine is observed above -0.94 and $-0.90 \mathrm{~V}$ vs. $\mathrm{Ag} / \mathrm{AgCl}$ on the cobalt and nickel substrates, respectively. This indicates that excess potential for the hydrazine oxidation is higher on the nickel substrate than on the cobalt substrate. The exchange current density of the hydrazine oxidation reaction is much smaller on the nickel substrate than on the cobalt substrate. Namely, nickel has a lower catalytic activity than cobalt in the oxidation reaction of hydrazine.

Both a weight of deposited metal and a total current density are simultaneously measured by voltammetry combined with QCM. The following reduction reaction of $\mathrm{Co}(\mathrm{II})$ and $\mathrm{Ni}(\mathrm{II})$ species was
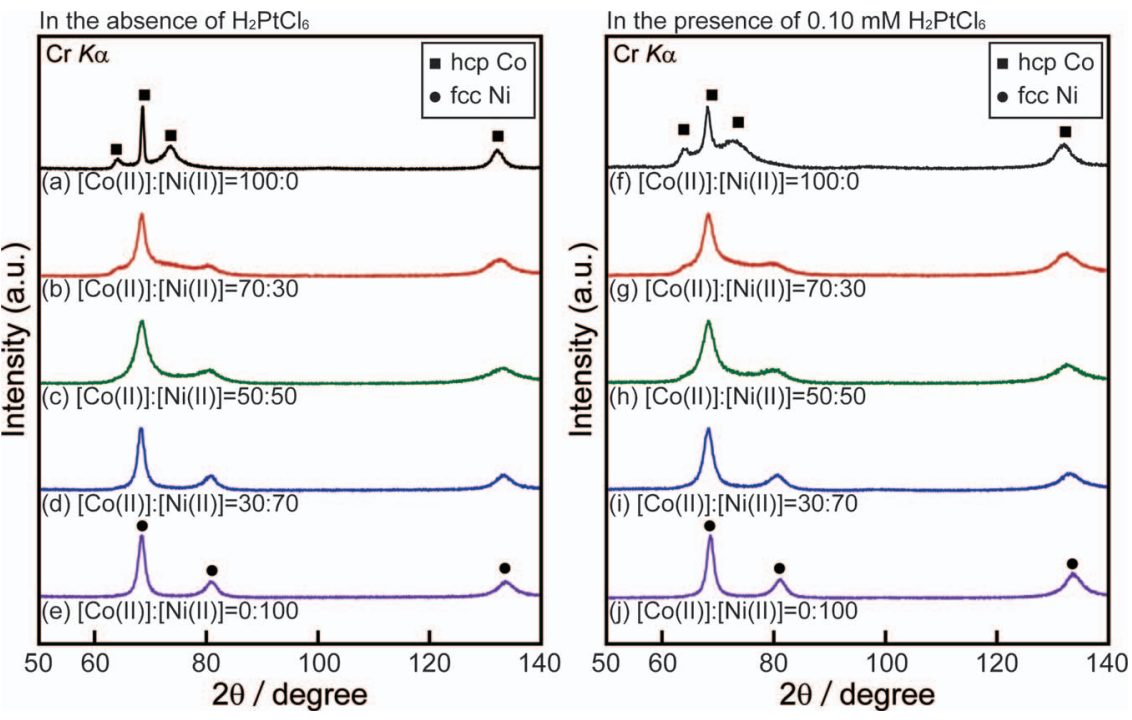

Figure 8. XRD patterns of the wires synthesized from the solutions containing (a) $0.050 \mathrm{M} \mathrm{Co}$ (II), (b) 0.035 M Co(II) $-0.015 \mathrm{M} \mathrm{Ni(II),} \mathrm{(c)} 0.025 \mathrm{M} \mathrm{Co}(\mathrm{II})-0.025$ $\mathrm{M} \mathrm{Ni(II),(d)} 0.015 \mathrm{M} \mathrm{Co}(\mathrm{II})-0.035 \mathrm{M} \mathrm{Ni}(\mathrm{II})$, and (e) $0.050 \mathrm{M} \mathrm{Ni}$ (II) in the absence $\mathrm{H}_{2} \mathrm{PtCl}_{6}$, and (f) 0.050 M Co(II), (g) $0.035 \mathrm{M} \mathrm{Co(II)} \mathrm{-} 0.015 \mathrm{M} \mathrm{Ni(II),(h)} 0.025$ $\mathrm{M}$ Co(II) $-0.025 \mathrm{M} \mathrm{Ni}(\mathrm{II}$ ), (i) $0.015 \mathrm{M}$ Co(II) $-0.035 \mathrm{M}$ $\mathrm{Ni}(\mathrm{II})$, and (j) $0.050 \mathrm{M} \mathrm{Ni}$ (II) in the presence of $0.10 \mathrm{mM}$ $\mathrm{H}_{2} \mathrm{PtCl}_{6}$. 


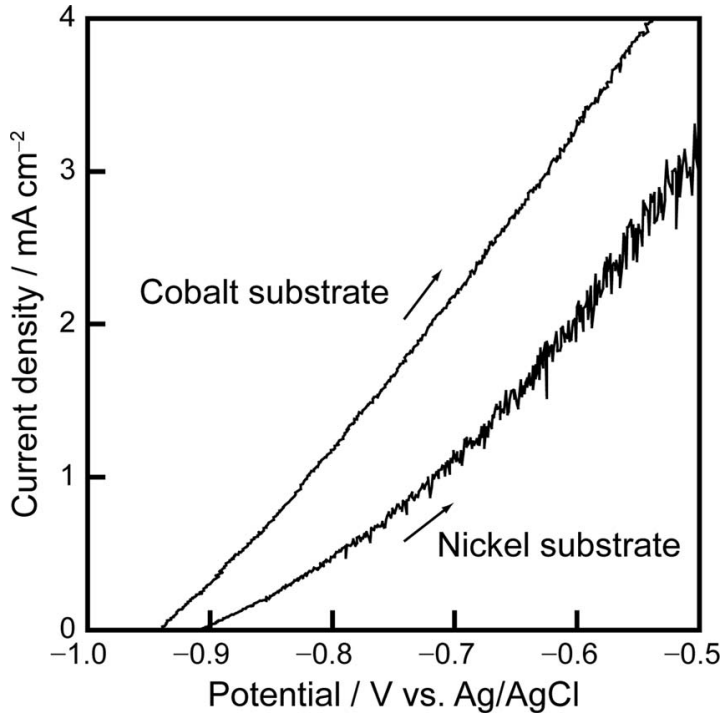

Figure 9. Anodic polarization curves measured on cobalt and nickel substrates in EG containing $0.2 \mathrm{M} \mathrm{NaOH}$ and $0.50 \mathrm{M} \mathrm{N}_{2} \mathrm{H}_{4}$. Sweep rate is $1 \mathrm{mV} \mathrm{s}^{-1}$.

separately evaluated from the weight change of metal deposited on the QCM substrate.

$$
\begin{aligned}
& \mathrm{Co}(\mathrm{II})+2 \mathrm{e} \rightarrow \mathrm{Co} \\
& \mathrm{Ni}(\mathrm{II})+2 \mathrm{e} \rightarrow \mathrm{Ni}
\end{aligned}
$$

Figure 10 shows cyclic voltammograms measured in $120 \mathrm{~cm}^{3} \mathrm{EG}$ containing $0.050 \mathrm{M} \mathrm{CoCl}_{2}$ and $0.2 \mathrm{M} \mathrm{NaOH}$ (Fig. 10a), and 0.050 $\mathrm{M} \mathrm{NiCl}_{2}$ and $0.2 \mathrm{M} \mathrm{NaOH}$ (Fig. 10b) using the gold-sputtered and nickel-sputtered QCM substrates as a working electrode, respectively. As shown in Fig. 10a (dotted line), the cathodic current due to the decomposition of the solvent is observed below about $-0.90 \mathrm{~V}$ vs. $\mathrm{Ag} / \mathrm{AgCl}$ during the cathodic sweep. The contribution of this reductive decomposition of the solvent to the total current density is dominant in this process, and the current density due to the cobalt deposition is hardly observed by a normal voltammetry. In a cyclic voltammogram evaluated from the weight change observed by QCM (Fig. 10a, solid line), the cathodic current due to the cobalt deposition is observed below about $-0.80 \mathrm{~V}$ during the cathodic sweep. After the gold-sputtered QCM substrate was completely covered with deposited cobalt, the deposition current of cobalt is observed below
$-0.77 \mathrm{~V}$ during the anodic sweep. The dissolution of cobalt was seen above $-0.77 \mathrm{~V}$. Thus, the redox potential of $\mathrm{Co}$ (II)/Co can be determined about $-0.77 \mathrm{~V}$. Similarly, the redox potential of $\mathrm{Ni}(\mathrm{II}) / \mathrm{Ni}$ is about $-0.70 \mathrm{~V}$, which is slightly more positive value than that of $\mathrm{Co}(\mathrm{II}) / \mathrm{Co}$. The reduction current density of $\mathrm{Ni}(\mathrm{II})$ species is much smaller than that of $\mathrm{Co}(\mathrm{II})$ species.

Consequently, both the anodic current density of hydrazine oxidation and the cathodic current density of metal deposition are smaller on nickel than on cobalt. Thus, it would appear that the growth rate of nickel particles is slower than that of cobalt particles. Once nickel deposits on the surface of particles in the formation process of $\mathrm{Co}-\mathrm{Ni}$ alloy particles, both the oxidation reaction of hydrazine and the deposition of metal are suppressed. Therefore, nickel has an inhibiting effect on the Co-Ni particle growth and the increase in the concentration of $\mathrm{Ni}(\mathrm{II})$ results in the decrease of growth rate of $\mathrm{Co}-\mathrm{Ni}$ particles.

A small composition gradient in the Co-Ni alloy particles as shown in Fig. 2 can be explained by these different electrode behaviors between cobalt and nickel in the reduction reactions of metallic ions and the oxidation reactions of hydrazine. The atomic ratio of cobalt is higher at the core of Co-Ni alloy particles than at the edge because the deposition of cobalt is preferentially occurred in the growth process. According to the Co-Ni alloy phase diagrams, the hcp phase is stable at a higher concentration of cobalt. It is likely that cobalt-rich core of particles mainly has the hcp phase and the edge of particles has the fcc phase. In the result, the mixture of hcp and fcc phases are observed in the XRD patterns of the as-prepared Co-Ni alloy particles and wires in Fig. 3b-3d and 3g-3i. During the annealing at $623 \mathrm{~K}$ for 16 hours, a composition gradient in the $\mathrm{Co}-\mathrm{Ni}$ alloy particles is reduced by atomic diffusion, which results in the disappearance of the hep phase and the grain growth of the fcc phase in the particles containing more than 25 atom\% $\mathrm{Ni}$.

Figure 11 shows the time-dependence of mixed potential in the solution containing $0.50 \mathrm{~N}_{2} \mathrm{H}_{4}, 0.2 \mathrm{M} \mathrm{NaOH}$, and (a) $0.050 \mathrm{M} \mathrm{CoCl}_{2}$ or (b) $0.050 \mathrm{M} \mathrm{NiCl}_{2}$. The redox potentials of $\mathrm{Co}(\mathrm{II}) / \mathrm{Co}$ and $\mathrm{Ni}(\mathrm{II}) / \mathrm{Ni}$ are also indicated. At $0.050 \mathrm{M} \mathrm{CoCl}_{2}$ (Fig. 11a), the mixed potential gradually dropped below the redox potential of $\mathrm{Co}(\mathrm{II}) / \mathrm{Co}$ after about 4 minutes of mixing the metallic salt solution and the hydrazine solution. This indicates that the cobalt deposition is thermodynamically possible at 4 minutes after the start of the reaction. Actually, the cobalt deposition is observed after 4 minutes of reaction by the in-situ QCM measurement as shown in Fig. 6a. At $0.050 \mathrm{M} \mathrm{NiCl}_{2}$ (Fig. 11b), the mixed potential quickly dropped to around $-1.04 \mathrm{~V} \mathrm{vs.} \mathrm{Ag} / \mathrm{AgCl}$ just after mixing the reaction solutions.

The difference between the redox potential and the mixed potential corresponds to the driving force of the metal deposition. Thus, the driving force of nickel metal deposition is higher than that of cobalt and the homogeneous nucleation is more favorable during the formation of
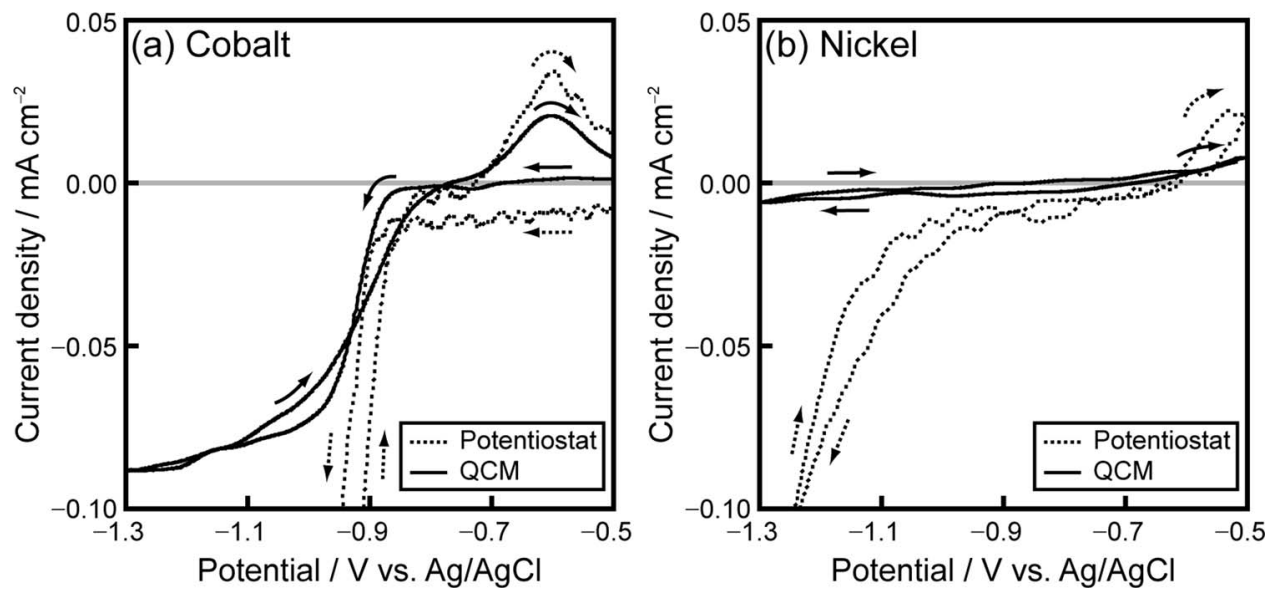

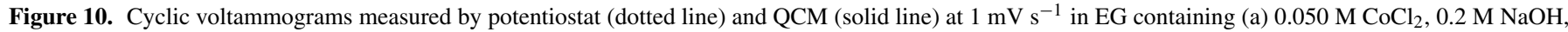
and (b) $0.050 \mathrm{M} \mathrm{NiCl}_{2}, 0.2 \mathrm{M} \mathrm{NaOH}$. 


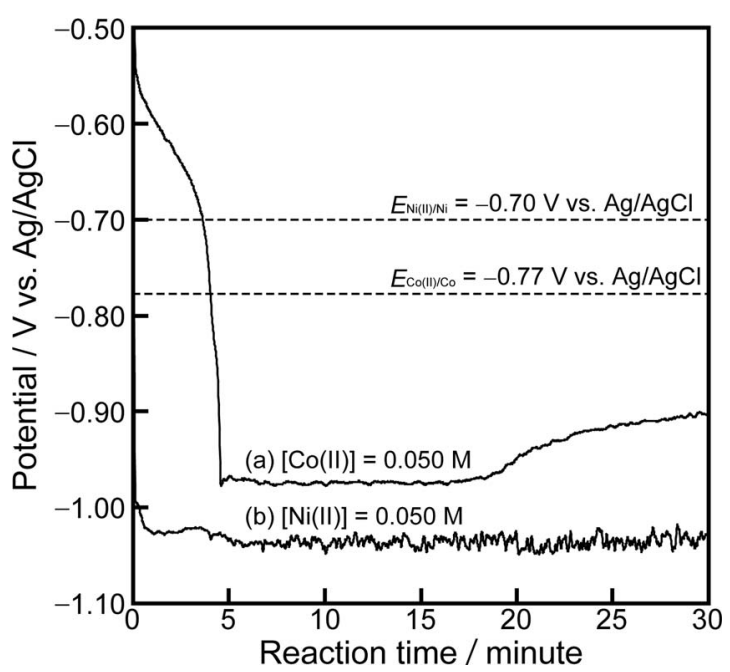

Figure 11. Time dependence of mixed potential in the solution containing

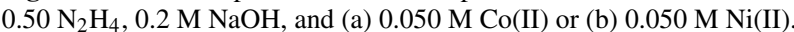

nickel particles than that of cobalt particles. Furthermore, the slower particle growth rate of nickel divides the nucleation and growth stage during the formation, which results in smaller particles with a sharper size distribution as shown in Figs. 1e and $1 \mathrm{j}$. An inhibiting effect on the Co-Ni particle growth by the addition of $\mathrm{Ni}(\mathrm{II})$ becomes stronger with increasing a concentration of $\mathrm{Ni}(\mathrm{II})$ and the nucleation is prompted in comparison. This is the formation mechanism of smaller particles by the addition of $\mathrm{Ni}$ (II).

Formation of Co-Ni nanowires under a magnetic field.- In the previous report, ${ }^{17}$ we discussed the following formation mechanism of nanowires via electroless deposition under a magnetic field. First, particles are formed in the reaction solution, and are aligned along a magnetic field due to the magnetic interaction among the particles. Then, the necks between particles are preferentially covered with deposited metal to decrease the interfacial energy. Finally, the particles are tightly connected and form rigid wires. Therefore, the necessary condition for the formation of wires is that the alignment of particles occurs prior to the terminal point of the deposition reaction. According

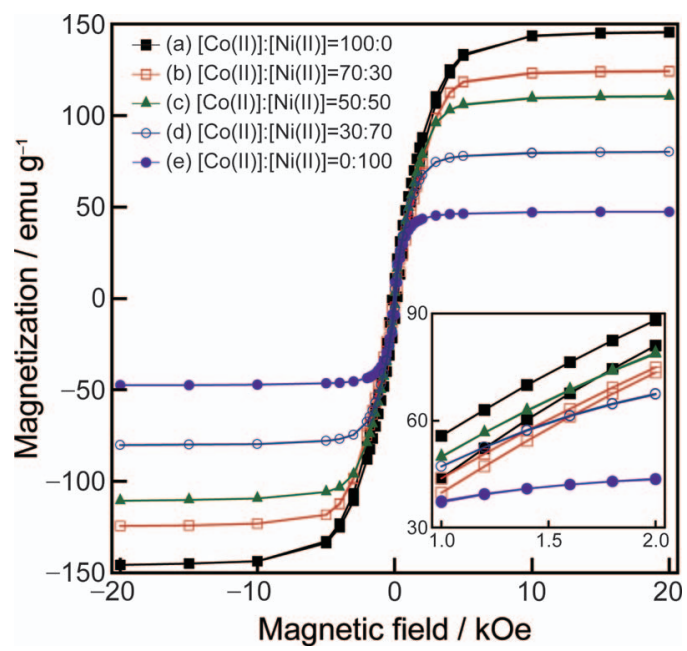

Figure 12. The magnetization-magnetic field $(\mathrm{M}-\mathrm{H})$ curves obtained at room temperature for the particles synthesized from the solutions containing (a) $0.050 \mathrm{M} \mathrm{Co}$ (II), (b) $0.035 \mathrm{M} \mathrm{Co}$ (II) $-0.015 \mathrm{M} \mathrm{Ni}$ (II), (c) $0.025 \mathrm{M} \mathrm{Co}$ (II) $0.025 \mathrm{M} \mathrm{Ni}$ (II), (d) $0.015 \mathrm{M} \mathrm{Co}$ (II) $-0.035 \mathrm{M} \mathrm{Ni}$ (II), (e) $0.050 \mathrm{M} \mathrm{Ni}$ (II) in the absence of $\mathrm{H}_{2} \mathrm{PtCl}_{6}$.

\begin{tabular}{lcc}
\hline $\begin{array}{l}\text { Table III. Magnetic properties of particles synthesized by } \\
\text { changing the concentration ratio of } \mathbf{C o}(\mathrm{II}) \text { and Ni(II) in the } \\
\text { reaction solution. }\end{array}$ \\
$\begin{array}{l}\text { Concentration ratio of metallic } \\
\text { species in the reaction solution }\end{array}$ & $\begin{array}{c}\text { Saturation } \\
\text { magnetization, } M_{s} \\
\left(\mathrm{emu} \mathrm{g}^{-1}\right)\end{array}$ & $\begin{array}{c}\text { Coercivity, } H_{c} \\
\text { (Oe) }\end{array}$ \\
[Co(II)] [Ni(II)] & 145.5 & 186 \\
\hline (a) $100: 0$ & 124.1 & 92 \\
(b) $70: 30$ & 110.3 & 41 \\
(c) $50: 50$ & 80.1 & 61 \\
(d) $30: 70$ & 47.5 & 102 \\
(e) $0: 100$ & &
\end{tabular}

to this mechanism, the magnetic interaction and the deposition rate of particles strongly affect the formation of wires. Namely, the formation of wires becomes easier at a stronger magnetic interaction and a slower deposition rate of particles.

Figure 12 shows the magnetization-magnetic field $(\mathrm{M}-\mathrm{H})$ curves for the particles synthesized by changing the concentration ratios of $\mathrm{Co}$ (II) to $\mathrm{Ni}$ (II) in solution without $\mathrm{H}_{2} \mathrm{PtCl}_{6}$. The hysteresis is observed in each curve and it would appear that the particles behave as magnetic multidomain particles. ${ }^{24}$ The magnetic properties of the particles are summarized in Table III. The saturation magnetization of cobalt and nickel particles is 145.5 and $47.5 \mathrm{emu} \mathrm{g}^{-1}$ which is lower than that of the bulk metal (161 and $54 \mathrm{emu} \mathrm{g}^{-1}$ at $293 \mathrm{~K}$, respectively). ${ }^{25}$ The saturation magnetization of $\mathrm{Co}-\mathrm{Ni}$ alloy particles decreases with increasing a concentration ratio of $\mathrm{Ni}(\mathrm{II})$. The decrease of the observed saturation magnetization of cobalt and nickel particles with respect to the bulk values is possibly due to the impurities such as carbon, oxygen, and hydrogen. ${ }^{24,26}$ Actually, the mass losses about $2 \%$ were observed in cobalt particles (Fig. 1a) after the thermal treatment at $623 \mathrm{~K}$ in $\mathrm{H}_{2}$ atmosphere for 16 hours, indicating that the particles contain the organic species, organometallic phases or unreacted hydroxides which are thermally unstable.

At 1.0-2.0 kOe, which corresponds to the magnetic field in the syntheses of wires, the magnetization of nickel particles is much lower than that of cobalt and Co-Ni alloy particles as shown in the inset of Fig. 12. In the formation of cobalt wires, it takes less time for the particles to align along a magnetic field due to the stronger magnetic interaction between cobalt particles. Thus, the particles align prior to the end of the reduction reaction and the relatively-smooth wires were formed as shown in Fig. $7 \mathrm{a}$ and $7 \mathrm{f}$ despite the higher growth rate of particles. On the contrary, the weak magnetic interaction between nickel particles results in the formation of beads-like wires as shown in Fig. 7 while the growth rate of nickel particles is lower than that of cobalt. In order to fabricate the nickel wires with a smooth surface, it is necessary to decrease the deposition rate of nickel particles, which is achieved ${ }^{17}$ by adjusting a concentration of $\mathrm{NaOH}$ and adding a complexing agent such as trisodium citrate dihydrate $\left(\mathrm{Na}_{3} \mathrm{C}_{6} \mathrm{H}_{5} \mathrm{O}_{7} \cdot 2 \mathrm{H}_{2} \mathrm{O}\right)$. Consequently, by carefully controlling both the deposition rate and the magnetization of the particles, one can successfully prepare nanowires with various diameters and surface morphology.

\section{Conclusions}

In the present work, the formation of Co-Ni particles and wires via electroless deposition was electrochemically investigated. The formation of smaller particles and thinner wires by the addition of $\mathrm{Ni}$ (II) is explained by different electrode behaviors between cobalt and nickel in the oxidation reaction of hydrazine and the reduction reactions of metallic ions. The catalytic activity of both reactions is much lower on nickel than that on cobalt, indicating that the growth rate of nickel particles is lower than cobalt. Deposited nickel suppresses the growth of Co-Ni particles. A small composition gradient observed in $\mathrm{Co}-\mathrm{Ni}$ alloy particles is also explained by the different deposition rate of 
cobalt and nickel. The magnetization of particles as well as the deposition rate strongly affects the morphology of wires formed under a magnetic field. For example, a lower deposition rate is required in fabrication of smooth wires whose magnetization is relatively weak, such as nickel.

\section{Acknowledgments}

This research was supported by a grant-in-Aid for JSPS (Japan Society for the Promotion of Science) fellows, grant-in-Aid for Knowledge Cluster Initiative (Kyoto Nanotechnology Cluster), grant-in-Aid for the Global COE Program (International Center for Integrated Research and Advanced Education in Materials Science), and grant-inAid for Challenging Exploratory Research (23656477), all from the Japan Society for the Promotion of Science, Ministry of Education, Culture, Sports, Science and Technology of Japan.

\section{References}

1. Y. Xia, P. Yang, Y. Sun, Y. Wu, B. Mayers, B. Gates, Y. Yin, F. Kim, and H. Yan, $A d v$ Mater, 15, 353 (2003).

2. X. Y. Zhang, L. D. Zhang, W. Chen, G. W. Meng, M. J. Zheng, L. X. Zhao, and F. Phillipp, Chem. Mater., 13, 2511 (2001).

3. K. Nielsch, F. Müller, A.-P. Li, and U. Gösele, Adv. Mater, 12, 582 (2000).

4. M. Tian, J. Wang, J. Kurtz, T. E. Mallouk, and M. H. W. Chan, Nano Lett., 3, 919 (2003).

5. F. Dumestre, B. Chaudret, C. Amiens, M. C. Fromen, M. J. Casanove, P. Renaud, and P. Zurcher, Angew. Chem., 114, 4462 (2002).

6. Z. Zhang, D. A. Blom, Z. Gai, J. R. Thompson, J. Shen, and S. Dai, J. AM. CHEM. SOC., 125, 7528 (2003).
7. D. Ung, Y. Soumare, N. Chakroune, G. Viau, M.-J. Vaulay, V. Richard, and F. Fiévet, Chem. Mater, 19, 2084 (2007).

8. Y. Soumare, A. Dakhlaoui-Omrani, F. Schoenstein, S. Mercone, G. Viau, and N. Jouini, Solid State Communications, 151, 284 (2011).

9. V. V. Sviridov, G. P. Shevchenko, A. S. Susha, and N. A. Diab, J. Phys. Chem., 100, 19632 (1996).

10. M. D. L. Balela, S. Yagi, and E. Matsubara, J. Electrochem. Soc., 158, D210 (2011).

11. S. Yagi, H. Nakanishi, E. Matsubara, S. Matsubara, T. Ichitsubo, K. Hosoya, and Y. Matsuba, J. Electrochem. Soc., 155, D474 (2008).

12. S. Yagi, H. Nakanishi, T. Ichitsubo, and E. Matsubara, J. Electrochem. Soc., 156, D321 (2009).

13. S. Yagi, M. Kawamori, and E. Matsubara, Electrochem. Solid-State Lett., 13, E1 (2010).

14. M. D. L. Balela, S. Yagi, and E. Matsubara, Electrochem. Solid-State Lett., 13, D4 (2010).

15. S. Yagi, T. Koyanagi, H. Nakanishi, T. Ichitsubo, and E. Matsubara, J. Electrochem. Soc., 155, D583 (2008)

16. S. Yagi, M. Kawamori, and E. Matsubara, J. Electrochem. Soc., 157, E92 (2010)

17. M. Kawamori, S. Yagi, and E. Matsubara, J. Electrochem. Soc., 158, E79 (2011).

18. A. Janshoff, H. J. Galla, and C. Steinem, Angew. Chem. Int. Ed., 39, 4004 (2000).

19. G. Viau, P. Toneguzzo, A. Pierrard, O. Acher, F. Fiévet-Vincent, and F. Fiévet, Scr. Mater, 44, 2263 (2001).

20. M. D. L. Balela, S. Yagi, Z. Lockman, A. Aziz, A. Jr. Amorsolo, and E. Matsubara, J. Electrochem. Soc., 156, E139 (2009).

21. M. Pourbaix, Atlas of Electrochemical Equilibria in Aqueous Solutions, p. 322, Cebelcor, Brüssel (1966).

22. T. Nishizawa and K. Ishida, Bull. Alloy Phase Diagram, 4, 390 (1983).

23. P. Villars and L. D. Calvert, Pearson's Handbook of Crystallographic Data for Intermetallic Phases, American Society of Metals, Materials Park, Ohio, (1985).

24. C. Luna, M. Morales, C. J. Serna, and M. Vazquez, Nanotechnology, 14, 268 (2003).

25. B. D. Cullity and C. D. Graham, Introduction to Magnetic Materials, Second Edition, p. 531, The Institute of Electrical and Electronics Enginners, Inc. (2009).

26. G. Viau, F. Fiévet-Vincent, and F. Fiévet, J. Mater. Chem., 6, 1047 (1996) 